\title{
OS VERBOS HAVER E TER EXISTENCIAIS EM DADOS DE FALA CULTA FORTALEZENSE: UMA ANÁLISE VARIACIONISTA ${ }^{1}$
}

\section{VERBS THERE TO BE AND TO HAVE IN DATA FROM FORTALEZA CULTURED SPEECH: A VARIATIONIST ANALYSIS}

\author{
VIANA, Rakel Beserra de Macêdo \\ Doutoranda e mestre em Linguística Aplicada - PosLA-UECE \\ Docente da Secretaria de Educação Básica do Ceará - SEDUC-CE \\ E-mail: rakelbeserra@gmail.com \\ ORCID ID: http://orcid.org/0000-0001-6565-7730
}

\section{ARAÚJO, Aluiza Alves de}

Doutora em Linguística pela UFC

Docente do Programa de Pós-Graduação em Linguística Aplicada - PosLA-UECE

E-mail: aluizazinha@hotmail.com

ORCID ID: http://orcid.org/0000-0003-2166-0852

\section{RESUMO:}

Com base na perspectiva da Sociolinguística Variacionista, analisamos a atuação de fatores linguísticos e sociais sobre a variação dos verbos existenciais haver e ter. Coletamos dados da fala de 50 informantes do corpus do projeto Português Oral Culto de Fortaleza - PORCUFORT e analisamos 09 variáveis linguísticas e 03 variáveis extralinguísticas. Os resultados da análise estatística revelaram que, de 2.268 dados, 461 (20,3\%) pertencem a haver e 1.807 (79,7\%) são de ter. Os grupos de fatores relevantes para o verbo haver foram, nessa ordem de importância: traço semântico do $S N$, tempo e modo verbal, tipo de registro, concordância entre o verbo e o $S N$, faixa etária, repetição do verbo no mesmo enunciado, presença de elementos à esquerda do verbo, sexo e posição do SN.

Palavras-chave: Verbos existenciais. Sociolinguística variacionista. Falar culto. Fortaleza-CE.

1 Esta pesquisa está vinculada ao Laboratório de Pesquisas Sociolinguísticas do Ceará (LAPESCE) do $\mathrm{CH}$ da UECE, coordenado pela professora Dra. Aluiza Alves de Araújo, docente vinculada à Linha 02 de pesquisa - Multilinguagem, Cognição e Interação do Programa de Pós-Graduação em Linguística Aplicada - PosLA da Universidade Estadual do Ceará - UECE, e ao Grupo de Estudos e Pesquisas sociolinguísticas de Fortaleza-CE (SOCIOFOR), vinculado ao Diretório de Grupos de Pesquisas do CNPq, coordenado pela mesma professora. 


\section{ABSTRACT:}

Based on the perspective of Variationist Sociolinguistics, we analyze the performance of linguistic and social factors on the variation of existential verbs there to be and to have. We collected data from the speech of 50 informants from the corpus of the Português Oral Culto de Fortaleza - PORCUFORT and analyzed 09 linguistic variables and 03 extralinguistic variables. The results of the statistical analysis revealed that, of 2,268 data, 461 (20.3\%) belonged to there to be and 1,807 $(79.7 \%)$ were of to have. The groups of factors relevant to the verb there to be were, in this order of importance: semantic trait of $\mathrm{SN}$, time and verbal mode, record type, agreement between the verb and the $\mathrm{SN}$, age group, repetition of the verb in the same statement, presence of elements to the left of the verb, gender and SN position.

Key words: Existential verbs. Variationist sociolinguistics. Cultured speech. Fortaleza-CE.

\section{INTRODUÇÃO}

Dentre as inúmeras pesquisas de fenômenos de variação linguística realizadas Brasil a fora, tratamos aqui, neste trabalho, da alternância entre os verbos existenciais ter e haver no português falado por pessoas com nível superior completo de Fortaleza-CE. Os verbos existenciais podem apresentar, em um mesmo contexto, o sentido de existência, ou seja, podemos usar qualquer um deles para referirmo-nos à existência de algo ou alguém.

Embora muitos estudos variacionistas já tenham sido realizados sobre o tema em questão (CALLOU; AVELAR, 2000; DUTRA, 2000; MARTINS; CALLOU, 2003; BERLINCK; DUARTE; OLIVEIRA, 2009; BATISTA, 2012; VITÓRIO, 2013; VIANA, 2018, dentre outros), nenhum ainda analisou o fenômeno em questão em dados da fala culta fortalezense, o que pretendemos sanar com a proposta em tela. Para essa empreitada, utilizaremos o corpus do único banco de dados de fala culta fortalezense, até então, o Projeto Português Oral Culto de Fortaleza - PORCUFORT Fase I² (doravante PORCUFORT), datado da década de 1990 (ARAÚJO; VIANA; PEREIRA, 2018a).

Dessa forma, nosso objetivo é analisar, embasados na Teoria da Mudança e Variação Linguística (LABOV, 2008; WEINREICH; LABOV; 
HERZOG, 2006), a variação no uso dos verbos existenciais haver e ter na amostra do PORCUFORT, verificando qual deles é mais produtivo na amostra, assim como, quais fatores, dentre os linguísticos e os extralinguísticos, favorecem uma ou outra variante, e por último, se há, na fala culta fortalezense, indícios de mudança no sentido de ter substituir haver.

Dentre nossas hipóteses, acreditamos que a ocorrência geral de ter seja superior a haver. Além disso, defendemos, ainda, que os tempos do presente, a presença de elementos à esquerda do verbo, os tipos de registro $D 2^{3}$, o sexo masculino e a menor faixa I sejam os fatores que mais favorecem o verbo ter. Já, em relação ao verbo haver, cremos que ele é beneficiado pelos seguintes fatores: pelo traço semântico do $S N$ [-animado], pelos tempos no passado, pela presença de modalizador, pela repetição do verbo no mesmo enunciado, através da presença da variável na fala do documentador, a partir do sexo feminino, a faixa etária III e pelo tipo de registro EF. Por último, supomos que estamos diante de uma avançada mudança em progresso, onde ter existencial está suplantando o uso de haver existencial e o próprio verbo existir.

Este artigo está organizado em seis seções, além das referências bibliográficas. Após esta introdução, a segunda seção é composta pela nossa Revisão de Literatura, o qual apresenta os principais resultados de quatro estudos variacionistas sobre o fenômeno que pesquisamos. A terceira aborda, brevemente, a teoria da Variação e Mudança linguística, base teórica desta pesquisa. A quarta seção traz a metodologia empregada, assim como descrição do corpus e da ferramenta estatística utilizados, além das variáveis testadas na análise. A quinta seção deste artigo apresenta e discute os resultados encontrados na pesquisa. Por fim, as considerações finais acerca dos resultados encontrados.

\section{OS EXISTENCIAIS NA FALA CULTA BRASILEIRA}

Diversos trabalhos sobre a variação de verbos existenciais, a partir de bancos de dados de fala culta, apresentam frequências de uso de haver superiores a frequências de bancos de dados de fala popular. Vejamos quatro desses trabalhos.

Callou e Avelar (2000) analisam dados de fala da cidade do Rio de Janeiro a partir do Projeto NURC, em um estudo de tendência, onde encontraram um total de 1.528 dados de haver e ter e, para a análise estatística, rodaram seus dados no pacote de programas Varbrul. Os 
grupos de fatores controlados na análise foram: sexo, faixa etária, década de gravação, tempo verbal e especificidade semântica do argumento interno. As variáveis relevantes estatisticamente foram: o tempo verbal, a especificidade semântica do argumento interno, a faixa etária e o sexo. No tempo verbal, a análise mostrou que o presente (0.60) privilegia ter para a década de 70 e 90, enquanto o passado favorece haver: (0.91) pretérito perfeito e (0.66) pretérito imperfeito para a década de 70 , e pretérito perfeito $(0.62)$ e pretérito imperfeito $(0.55)$ para a década de 90 ; na especificidade semântica do argumento interno, o traço [- material] beneficia o uso de haver e o traço [+ material] promove o uso de ter; já, na faixa etária, quanto mais velho o falante, maior aliado de haver; e para o sexo: para os autores, "foi possível ainda constatar que, na década de 70, as mulheres utilizam mais o ter do que os homens" (CALLOU; AVELAR, 2000, p. 94, grifos nossos).

Dutra (2000) analisou ter e haver na fala culta de Salvador, também a partir de dados do NURC. Sua amostra é composta por 32 informantes estratificados em dois gêneros, quatro faixas etárias e dois tipos de registro. A autora computou um total de 781 ocorrências de construções existenciais com ter e haver, sendo 484 ocorrências de ter (61,9\%) e 297 de haver (38,1\%). A autora utilizou o pacote de programas Varbrul, mas não apresenta pesos relativos, detendo-se apenas nas frequências. As 11 variáveis testadas foram as sociais: faixa etária e gênero, a extralinguística: tipo de registro, e as linguísticas: animacidade; natureza do objeto; flexão de número; tempo e modo verbal; posição do objeto; tipo de oração; constituição do SN objeto.

A autora, ao analisar todas as variáveis supracitadas, chegou aos seguintes resultados: para a variável faixa etária: haver predomina em frequência na faixa etária 3 com 57,6\% das ocorrências; gênero: o verbo haver apresenta 45,4\% das ocorrências com os homens, tipo de registro: no DID, ter obteve $76,5 \%$ e haver $23,5 \%$, já, no EF, ter obteve $37,3 \%$ e haver $62,7 \%$, revelando que, quanto mais formal o registro, maior é o uso de haver, animacidade: o verbo ter possui as maiores frequências ([+animado] 83,05\% e [- animado] 58,2\%), sendo que haver obteve maiores índices para o traço [- animado] $(41,8 \%)$, natureza do objeto: no fator traço abstrato, verificou-se o seguinte: o verbo ter obteve $35,1 \%$ de ocorrências, enquanto haver obteve $64,9 \%$, já, para o fator traço concreto, ter obteve $74,7 \%$ dos dados e haver $25,3 \%$, flexão de número: com haver, as frequências de ocorrência são reduzidas, sendo $38,1 \%$ e $35,7 \%$ respectivamente, tempo de modo verbal: nos DID, há 
predomínio do verbo haver no pretérito perfeito do indicativo e no presente do subjuntivo, nos EF, o verbo haver se sobressai em todos os modos e tempos verbais, sendo bastante expressivo no futuro do presente $(87,5 \%)$, no pretérito perfeito do indicativo $(83,3 \%)$, no infinitivo $(83,3 \%)$ e no pretérito imperfeito do indicativo $(73,5 \%)$, posição do objeto: para haver, as frequências são menores (38,4\% e 30,4\%) para objeto posposto e anteposto, tipo de oração, o verbo ter possui maiores índices de ocorrências em orações absolutas e haver possui os maiores índices nas orações subordinadas adverbiais (77,5\%) e substantivas $(57,8 \%)$, constituição do SN objeto: haver apresentou 94,1\% de frequências de tipos $\mathrm{SN}=\mathrm{DET}+\mathrm{N}+\mathrm{SA}+\mathrm{SP}$ e $71,4 \%$ de $\mathrm{N}+\mathrm{SA}^{4}$.

Ainda com dados do NURC, do Rio de Janeiro e de Salvador, Martins e Callou (2003) encontraram 2.036 ocorrências para haver e ter e apresentaram apenas as frequências. As variáveis testadas foram: sexo, faixa etária, década de gravação, tempo verbal e especificidade semântica do argumento interno. Para a análise estatística, as autoras utilizaram o pacote de programas Varbrul. As variáveis selecionadas por relevância foram o tempo verbal, especificidade semântica do argumento interno, faixa etária e sexo.

Para o sexo: as autoras afirmam que, em Salvador, nas faixas etárias 1 e 2, a "mudança" de ter por haver "já foi efetivada", e, na faixa 3, a frequência de ter existencial é de 97\% (MARTINS; CALLOU, 2003, p. 821); já, no Rio de Janeiro, as frequências para as duas décadas, na primeira faixa etária, são superiores a segunda e terceira. Quanto à varável sexo, a autora diz que "comprova-se, mais uma vez, que são as mulheres que tendem a liderar os processos não-estigmatizados de mudança lingüística e que quanto mais jovem o falante, maior a freqüência de uso de ter" (MARTINS; CALLOU, 2003, p. 822); quanto ao tempo verbal, o tempo presente é aliado de ter, enquanto o passado beneficia haver. Para o Rio de Janeiro, a frequência de ter no pretérito perfeito chega a apenas 10\% na década de 1970 e 35\% em 1990, enquanto que, no presente, ter alcança $70 \%$ e $90 \%$, respectivamente; já, no pretérito imperfeito, a frequência não se altera de uma década para outra, mantendo-se em torno de 65\%. Em Salvador, na década de 1970, o pretérito perfeito do indicativo colabora para com a ocorrência de haver, mesmo que o número de ocorrências de ter e haver apresente um certo equilíbrio: $57 \%$ de ter e $43 \%$ de haver. O imperfeito do indicativo

4 Legenda: $\mathrm{SN}$ - sintagma nominal; pro - pronome; $\mathrm{SA}$ - sintagma adjetival; $\mathrm{SP}$ - sintagma preposicional; $\mathrm{S}$ - sentença; DET - determinante; $\mathrm{N}$ - nome. 
e do subjuntivo, na década de 70, apresenta mais ocorrências de ter com $88 \%$ de casos e haver com $12 \%$. Na década de 90 , o imperfeito apresenta mais ocorrências de haver com 36\%; para a especificidade semântica do argumento interno, o traço [- material] colabora com o uso de haver, já o traço [+ material] promove o uso de ter.

Para as autoras, as duas cidades apresentam inserção de ter no campo de haver, sugerindo uma mudança em progresso: no Rio de Janeiro, a frequência do verbo ter sobe de $63 \%$, na década de 1970, para $76 \%$ na década de 1990; já, em Salvador, ter salta, na década de 1970, de $74 \%$ para $86 \%$ na década de 1990 .

Batista (2012) apresenta uma análise em tempo real, em tendência com ter e haver existenciais, no falar culto de Rio de Janeiro, Salvador e Porto Alegre, a partir de dados do NURC. A autora analisou 1.283 dados de construções existenciais das décadas de 70 e 90, apresentando-os em frequências. Os grupos de fatores testados foram: sexo, faixa etária, década de gravação, cidade, tempo verbal e natureza semântica do argumento interno.

Neste estudo, a seleção das variáveis relevantes pelo pacote de programas Varbrul, por década, para o verbo ter, são: a faixa etária faixa 1 é a que mais aplica ter nas duas décadas (82\% dec. 1970 e 99\% dec. 1990); o tempo verbal - o tempo presente e o pretérito perfeito em Salvador (85\% e $88 \%)$; e a natureza semântica do argumento interno [+ humano] e [+ material].

Ou seja, esses fatores promovem o uso de ter em ambas as décadas e nas três cidades. Para a autora, o uso de haver em construções existenciais pode ser interpretado como uma habilidade adquirida durante o aprendizado da escrita e a autora ainda assinala uma mudança em curso nas três cidades.

Vejamos, a seguir, uma breve apresentação bases teóricas da nossa pesquisa.

\section{TEORIA DA VARIAÇÃO E MUDANÇA LINGUÍSTICA}

A Teoria da Variação e Mudança Linguística vai de encontro a alguns fundamentos de outras correntes da linguística, que se preocupam, como Saussure, em estudar a língua em seus aspectos estruturais, defendendo a homogeneidade e ditando a heterogeneidade da língua como elemento caótico e incontrolável. Em sentido contrário, Camacho (2001, p. 69) afirma que "a heterogeneidade não é [...] uma propriedade inerente e funcional" da língua e afirma, ainda, que ela é a "capacidade 
de operar uma seleção entre formas alternativas possíveis, conforme as circunstâncias sociais da interação" (2001, p. 69), que é o que chama de "atributos mais relevantes da competência comunicativa do falante" (2001, p. 69). A sociolinguística defende não só a heterogeneidade linguística, mas também a toma como objeto de estudo.

Segundo Labov, "a existência de variação e de estruturas heterogêneas nas comunidades de fala investigadas está certamente bem fundamentada nos fatos (...) a heterogeneidade não é apenas comum, ela é o resultado natural de fatores linguísticos fundamentais" (2008, p. 238). Weinreich, Labov e Herzog (2006) ainda afirmam que a língua dispõe de estratos para cada grupo real de falantes, ou seja, que ela é multiestratificada. Dessa forma, a variedade e a heterogeneidade são, portanto, propriedades inerentes dos sistemas linguísticos e o papel da Sociolinguística é estudar, examinar e tratar essas variedades como objeto de estudo em suas categorizações linguísticas e não linguísticas.

A Sociolinguística Variacionista é caracterizada pelo estudo das variáveis extralinguísticas e sua direta correlação com as variáveis linguísticas (TARALLO, 1990), pois Labov (2008) acredita na Linguística sendo necessariamente uma ciência social. Fica evidente, para o pesquisador, portanto, que "as variáveis, tanto linguísticas quanto não linguísticas, não agem isoladamente, mas operam num conjunto complexo de correlações que inibem ou favorecem o emprego de formas variantes semanticamente equivalentes" (MOLLICA, 2004, p. 27).

A língua oferece a seus falantes diferentes possibilidades de expressarem-se e fazerem tudo o que se lhe esteja inserido socialmente a partir da linguagem. O que importa é desmistificar "o mito de que a língua-uso, na comunidade, é (ou precisa ser) um todo homogêneo (ou homogeneizado), que necessita de zelos e de leis" (MENDES, 2015, p. 132). Cada uma dessas possibilidades de uso da língua traz um valor que desempenha alguma função na realização da fala e na interação pessoal.

Vejamos, posto tudo isso, a metodologia empregada em nossa pesquisa, assim como a apresentação de nossa amostra e do programa computacional utilizado.

\section{METODOLOGIA}

O banco de dados selecionado como provedor de dados para nossa pesquisa é o Projeto Português Oral Culto de Fortaleza PORCUFORT, constituído por 73 informantes estratificados de acordo com o sexo, a faixa etária e o tipo de registro, concebido com o objetivo 
de figurar como um banco de dados da variedade urbana culta falada pelos fortalezenses (ARAÚJO; VIANA; PEREIRA, 2018a). Elaborado nos moldes do projeto NURC, o PORCUFORT constitui-se, hoje, como o único corpus representativo da norma culta falada em Fortaleza e encontra-se totalmente transcrito e digitalizado. Os indivíduos dessa data base têm, como características sociais, serem fortalezenses natos, filhos de pais fortalezenses ou pelo menos de mães fortalezenses e pais cearenses; nunca se ausentaram de Fortaleza por, no máximo, dois anos consecutivos; possuem graduação completa e, em sua grande maioria, já estavam inseridos no mercado de trabalho (ARAÚJO; VIANA; PEREIRA, 2018a).

Dessa forma, nossa amostra será baseada na análise estratificada e composta da seguinte forma: faixa etária: I (22 a 35 anos), II (36 a 50 anos) e III (51 anos em diante), sexo: masculino e feminino e tipo de registro: D2 - Diálogo entre Dois Informantes, DID - Diálogo entre Informante e Documentador e EF - Elocução Formal.

Vejamos, no quadro 1, a estratificação dos informantes de nossa amostra, de acordo com o controle de variáveis extralinguísticas (sexo, faixa etária e monitoramento estilístico) do PORCUFORT.

\begin{tabular}{|c|c|c|c|c|c|c|}
\hline \multirow[b]{3}{*}{$\begin{array}{l}\text { Tipo de Registro } \\
\text { Faixa etária }\end{array}$} & \multicolumn{6}{|c|}{ Sexo } \\
\hline & \multicolumn{3}{|c|}{ Masculino } & \multicolumn{3}{|c|}{ Feminino } \\
\hline & D2 & DID & EF & D2 & DID & EF \\
\hline $\begin{array}{c}I \\
\text { (22 a } 35 \text { anos) }\end{array}$ & 3 & 3 & 3 & 3 & 3 & 3 \\
\hline $\begin{array}{c}\text { II } \\
\text { (36 a } 50 \text { anos) }\end{array}$ & 3 & 3 & 3 & 3 & 2 & 2 \\
\hline $\begin{array}{c}\text { III } \\
\text { (51 anos acima) }\end{array}$ & 3 & 3 & 3 & 3 & 3 & 1 \\
\hline Total & 9 & 9 & 9 & 9 & 8 & 6 \\
\hline Total geral & \multicolumn{6}{|c|}{50} \\
\hline
\end{tabular}

Fonte: Adaptado de Araújo, Viana e Pereira (2018a).

Portanto, nossa amostra será composta por 50 falantes, sendo, destes, 17 indivíduos dos inquéritos DID, 18 indivíduos dos inquéritos D2 e 15 indivíduos do EF do PORCUFORT, como apresentado no Quadro 1.

As 12 variáveis testadas na análise foram as linguísticas: traço semântico do $S N$, preenchimento de elementos à esquerda do verbo, 
tipo de oração, posição do $S N$, peso do $S N$, tempo e modo verbal, presença de modalizador, repetição do verbo no mesmo enunciado, e concordância entre o verbo e o $S N$. Já as variáveis extralinguísticas foram: faixa etária, sexo ${ }^{5}$ e tipo de registro, como na estratificação do corpus.

Os dados deste trabalho foram coletados não só por meio da sua identificação durante a leitura das entrevistas transcritas, com a utilização da ferramenta "localizar" do programa Microsoft Word, mas também através da audição, na íntegra, dos inquéritos selecionados, o que garantiu maior confiabilidade à coleta de dados. Coletadas as orações que continham os verbos em questão, codificamos todos os dados e os submetemos à análise estatística do programa computacional Goldvarb X (SANKOFF; TAGLIAMONTE; SMITH, 2005) que verifica a chance de um fator influenciar a ocorrência de uma ou outra variante.

A seguir, apresentamos os resultados obtidos para haver vs. ter em sentido existencial.

\section{DISCUSSÃO E ANÁLISE DOS RESULTADOS}

Nossa análise binária é sobre os dados relativos aos verbos haver e ter, lembrando que sempre em sentido existencial e com aplicação para a variante padrão, haver. Encontramos um total de 2.268 ocorrências, sendo 461 dados de haver (20,3\%) e 1.807 dados de ter $(79,7 \%)$, como mostram as frequências no Gráfico 1.

Gráfico 1 - Frequências das variantes haver vs. ter em nossa amostra

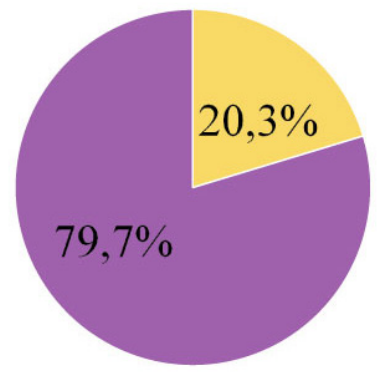

\section{Haver}

Ter

Fonte: elaboração própria.

$5 \quad$ Frisamos que utilizamos a palavra sexo para designar o traço biológico dos informantes, assim como pré-estabelecido no banco de dados. 
Após verificadas as frequências como apresentadas no Gráfico 1, a rodada do Goldvarb X para haver vs. ter trouxe-nos somente um nocaute na variável tempo e modo verbal, no fator futuro do presente do indicativo, com 01 dado apenas para haver. Após nocaute resolvido, com a exclusão, no arquivo de condições, dos dados relativos aos nocautes, prosseguimos a análise. Os resultados sugeridos pelo Goldvarb X, para haver vs. ter foram extraídos do Run \# 62, com a Convergence at Iteration 8, que nos deu um Input de 0,141, com significância de 0,017 e Log likelihood de -901,311.

O Goldvarb X selecionou 09 variáveis relevantes para a manutenção de haver em construções existenciais na fala culta de Fortaleza-CE, que foram os seguintes grupos de fatores: traço semântico do $S N$, tempo e modo verbal, tipo de registro, concordância entre o verbo e o $S N$; faixa etária; repetição do verbo no mesmo enunciado; presença de elementos à esquerda do verbo, sexo e posição do $S N$, nesta ordem de relevância. E, como variáveis desconsideradas na análise, estão o peso do $S \mathrm{~N}$ e a presença de modalizador.

Vejamos, a seguir, os resultados para cada variável selecionada como favorecedora de haver, por ordem de relevância.

\section{Traço semântico do Sintagma Nominal - SN}

A primeira variável selecionada em relevância para haver vs. ter, o traço semântico do $S N$ traz dados que corroboram resultados já encontrados em diversos estudos variacionistas ${ }^{6}$ sobre os verbos em estudo. Vejamos esses ${ }^{7}$ resultados para esse grupo de fatores na Tabela 1.

Tabela 1 - Atuação da variável traço semântico do SN sobre o verbo haver

\begin{tabular}{cccc}
\hline FATORES & Aplica/total & Percentual & P.R. \\
\hline [-animado] e [-concreto] & $287 / 932$ & $30,7 \%$ & $\mathbf{0 , 6 7 7}$ \\
[-animado] e [+concreto] & $129 / 859$ & $15 \%$ & 0,435 \\
[+animado] e [-humano] & $6 / 37$ & $16,2 \%$ & 0,428 \\
[+animado] e [+humano] & $39 / 438$ & $8,9 \%$ & 0,263 \\
\hline Input 0,141 & \multicolumn{3}{c}{ Significance $=0,017$}
\end{tabular}

Fonte: elaboração própria.

6 Traremos em caráter comparativo, apenas os resultados de estudos variacionistas sobre os verbos existenciais e seus respectivos dados apresentados na seção de Revisão da Literatura.

$7 \quad$ Nas tabelas apresentadas no texto, os números dos PRs destacados em negrito referem-se aos fatores favorecedores da variante de aplicação; os PRs destacados com negrito e sublinhado representam os fatores neutros, ou pouco acima do ponto neutro, em função da regra de aplicação; já, aqueles PRs sem destaque são os fatores desfavorecedores da aplicação, aliados da outra variante. 
Verificamos, na Tabela 1, que os traços [-animado] e [-concreto] são aliados de haver com o PR de 0,677, enquanto que os traços [-animado] e [+concreto] $(0,434)$, [+animado] e [-humano] $(0,428)$ e [+animado] e [+humano] $(0,263)$ inibem a variante padrão, resultados que confirmam nossas hipóteses tanto para haver quanto para ter.

Resultados semelhantes aos nossos são encontrados em Batista (2012), Callou e Avelar (2000), Dutra (2000) e Martins e Callou (2003), quando nos afirmam que traços do SN [+abstratos], [-humanos], [-material] e [-animado] são aliados do uso de haver pelo falante.

Válido ressaltar aqui que, analisando a Tabela 1, vemos ainda que os fatores inibidores de haver são, automaticamente, favorecedores de $\operatorname{ter}^{8}$, o que também é corroborado em Batista (2012), Callou e Avelar (2000), Martins e Callou (2003) e Dutra (2000), pois esses estudos nos dizem que os traços [+humano], [+material], [+animado] e [+concreto] são beneficiadores do verbo ter.

Esses resultados a que chegamos, confirmados pelos estudos supracitados, nos mostram uma certa dualidade entre os verbos haver vs. ter: quanto [+abstratos], [-concreto], [-animado] e [-humanos] o traço do $\mathrm{SN}$, mais beneficiador do verbo haver, enquanto que, do contrário, quanto [-abstratos], [+concreto], [+animado] e [+humano] o traço do $\mathrm{SN}$, mais beneficiador do verbo ter.

Os excertos abaixo ilustrarão cada fator do traço semântico do SN na fala dos fortalezenses ${ }^{9}$.

(6) tão quando eles /tã o lá que se de/... se dePAram com:: num tem castigo mas o castigo eh::... é o traBA::lho é:: a LUta né?... (PORCUFORT, DID, 13)

(7) tem a igreja da GLÓria que fica assim::... num Alto num:: (PORCUFORT, DID, 32)

(8) ...e::las falavam MUlto a gente perguntava eh e:.... "lobisomem eXISte?... e caiPOra eXISte?" e tudim confirmava né? conTA::va as his\{Tória (PORCUFORT, DID, 106)

(9) e HÁ OUtros jovens... aí com esses OUtros jovens também vai ocorrer esta mudança... (PORCUFORT, EF, 38)

8 É válido lembrar ao leitor que, em uma análise binária, ou seja, entre duas variantes, caso a variante de aplicação $A$ obtiver PR de 0,600 , a variante $B$ obterá, logicamente, um PR de 0,400 , pois esses números são menores que 1 e, juntos, somam 1.

9 Para melhor visualização, os excertos apresentados estarão, sempre, na ordem apresentada na disposição dos fatores das respectivas e referidas tabelas. 
Um fato curioso em nossa coleta e relacionado a essa variável, é que, em muitos casos, para atribuir o traço semântico do $\mathrm{SN}$, é necessário apelarmos para o contexto da fala do indivíduo. Um exemplo disso é quando um informante se refere a um funcionário, uma pessoa específica, de um banco como "caixa de banco", como podemos ver no excerto abaixo:

(10) num vou rasgar um cheque... vou dar pra ela porque tem caixa de banco que ainda aceita né?... (PORCUFORT, D2, 11, Inf. 01)

Durante nossa coleta de dados, buscamos, inicialmente, o sentido expresso pelo substantivo, mas quando este muda de campo semântico, no caso do excerto (10), de um objeto, a caixa, para uma pessoa, a funcionária, analisamos o sentido empregado no contexto do diálogo dos informantes.

Vejamos, a seguir, a continuidade de nossa análise com as demais variáveis relevantes.

\section{Tempo e modo verbal}

Outro grupo de fatores que sempre aparece dentre os relevantes para a variação dos verbos haver e ter é o tempo e modo verbal empregado nas variantes no momento da interação entre os informantes. Vejamos a atuação da segunda variável, em ordem de relevância, na Tabela 2 a seguir.

Tabela 2 - Atuação da variável tempo e modo verbal sobre o verbo haver

\begin{tabular}{cccc}
\hline FATORES & Aplica/total & Percentual & P.R. \\
\hline pretérito perfeito do indicativo & $84 / 169$ & $49,7 \%$ & $\mathbf{0 , 8 3 7}$ \\
pretérito imperfeito do subjuntivo & $12 / 30$ & $40 \%$ & $\mathbf{0 , 6 9 3}$ \\
formas nominais & $60 / 195$ & $30,8 \%$ & $\mathbf{0 , 5 6 6}$ \\
futuro do subjuntivo & $3 / 35$ & $14,3 \%$ & $\mathbf{0 , 5 1 2}$ \\
pretérito imperfeito do indicativo & $81 / 474$ & $17,1 \%$ & $\mathbf{0 , 5 0 7}$ \\
presente do indicativo & $215 / 1337$ & $16,1 \%$ & 0,437 \\
presente do subjuntivo & $2 / 16$ & $12,5 \%$ & 0,280 \\
futuro do pretérito do indicativo & $1 / 11$ & $9,1 \%$ & 0,205 \\
futuro do presente do indicativo & $1 / 1$ & \multicolumn{3}{c}{ nocaute } \\
\hline Input 0,141 & \multicolumn{3}{c}{ Significance 0,017}
\end{tabular}

Input 0,141

Significance 0,017

Fonte: elaboração própria. 
A Tabela 2 nos diz que os fatores pretérito perfeito do indicativo, pretérito imperfeito do subjuntivo e formas nominais são favorecedoras de haver com PRs de 0,873, 0,693 e 0,566 respectivamente, que confirmam nossa hipótese de que os tempos do passado privilegiaram o verbo haver. Já os fatores futuro do subjuntivo e pretérito imperfeito do indicativo também são aliadas da regra, mas, de forma discreta, com PRs pouco acima do ponto neutro: 0,512 e 0,507 respectivamente.

Como fatores desfavorecedores de haver, encontramos os seguintes: presente do indicativo $(0,437)$, presente do subjuntivo $(0,280)$ e futuro do pretérito do indicativo $(0,205)$, que são, automaticamente, favorecedores de ter.

Vejamos, a seguir, um excerto de nosso corpus para cada fator aliado de haver.

(11) e e me diz uma coisa houve aqui exportação de atleta p/ o sul do país aqui \{no Ceará? (PORCUFORT, D2, 34, Inf. 02)

(12) EU ACHO o seguinte se NUM houvesse na realidade prova então que a Secretaria (PORCUFORT, D2, 16, Inf. 02)

(13) uma... digamos esTÁ haVENdo:: um momento desemprego na faixa etária (PORCUFORT, D2, 30, Inf. 01)

(14) se hou/ se houVER... uma viagem quem paga são os alunos... no caso do inventário que a gente teve que faZER... (PORCUFORT, DID, 106)

(15) ... e queriam busCAR as inovações que já estavam... já já havia-se os rumores que vinha da FRANça... mas entre... Coimbra E França não havia uma intercomunicação tão boa... ATÉ que o governo... inaugurou:.... (PORCUFORT, $\mathrm{EF}, 36)$

Lembrando-nos dessas formas, vemos que estamos falando de houve, houvesse, haver/havendo/havido, (quando/se) houver e havia como as formas que mais foram beneficiadas na variação, de um lado, enquanto, do outro, estão no verbo ter, as formas ter, tenha e teria.

Fazendo uma relação com nossa revisão de literatura, averiguamos que não há consenso sobre os fatores delimitados na variável relacionada aos tempos e modos verbais, ou seja, há pesquisas que testam vários fatores, como mais de um pretérito e mais de um presente, etc., e há outras que testam apenas dois, como apenas a dualidade entre presente e pretérito. 
Dessa maneira, podemos dizer que as formas pretérito perfeito do indicativo, pretérito imperfeito do subjuntivo, futuro do subjuntivo, pretérito imperfeito do indicativo e formas nominais, aliadas de haver, também são confirmadas nos estudos de Batista (2012), e Dutra (2000), mesmo que usando o pretérito enquanto hiperônimo paras os demais pretéritos, como em Martins e Callou (2003) e Dutra (2000).

Encontramos, no estudo de Dutra (2000), uma única contradição com nossos resultados, quando a autora nos apresenta o presente do subjuntivo como beneficiador de haver, o que vem de encontro aos nossos resultados, embora devamos ressaltar que Dutra (2000) não apresenta PR em seus resultados, apenas as frequências.

\section{Tipo de Registro}

A variável tipo de registro, também analisada por Dutra (2000), foi relevante em todas as nossas análises sobre os verbos existenciais. Nesta análise de haver vs. ter, esse grupo de fatores mostrou-se em terceiro lugar geral de relevância e a primeira dentre as extralinguísticas. Vejamos sua atuação em nossos dados na Tabela 3.

\section{Tabela 3 - Atuação da variável tipo de registro sobre o verbo haver}

\begin{tabular}{cccc}
\hline FATORES & Aplica/total & Percentual & P.R. \\
\hline Elocução Formal - EF & $192 / 523$ & $36,7 \%$ & $\mathbf{0 , 7 6 5}$ \\
Diálogo entre Dois Informantes - D2 & $127 / 714$ & $17,8 \%$ & 0,478 \\
Diálogo entre Informante e Documentador - DID & $141 / 1030$ & $13,7 \%$ & 0,369 \\
\hline
\end{tabular}

Significance 0,017

Fonte: elaboração própria.

Nossos resultados apontam que apenas o registro $E F$ é beneficiador de haver com PR de 0,767 , enquanto que $D 2(0,478)$ e $D I D(0,369)$ são aliados de ter.

Sabemos que os EFs são os inquéritos mais formais dentre os três no PORCUFORT, pois "É composto, geralmente, por aulas, exposições e conferências nos quais os informantes mantêm um nível muito elevado de monitoramento da própria fala." (VIANA, 2018), o que faz os informantes, geralmente, buscarem a norma padrão da língua, escolhendo as variantes de prestígio que, em nosso caso, trata-se do verbo haver. Para essa variável, nossa hipótese de que o EF seria aliado de haver foi confirmada. 
Quando chamamos atenção para a questão do monitoramento estilístico, não deixamos de lado, porém, que embora haja a preferência por haver dentre os inquéritos, o verbo ter é sempre a variante que contém as maiores frequências de uso em todos os inquéritos e em todas as variáveis analisadas por nós.

Como já foi bastante explanado na seção de metodologia, há muitas diferenças entre os tipos de inquérito do corpus que utilizamos. Diferenças essas que podem também ser classificadas como diferenças de estilo. Hora (2014) nos alerta que, para Labov, o vernáculo do falante é fundamental, ou seja, sua fala mais natural, aquela que surge quando o indivíduo não a monitora. Dessa forma, Labov

[...] Estabelece níveis de formalidade ou informalidade na obtenção dos dados, que permitem avaliar possíveis indícios de mudança na língua quando o estilo é alterado. Assim, ele esboça a entrevista sociolinguística de forma que possa obter do falante, tanto quanto possível, uma fala que vá da mais casual à mais formal. (HORA, 2014, P. 21).

Ainda segundo Hora (2014), estudiosos da Sociolinguística, da Etnografia da Fala e de campos relacionados à variação linguística sugeriram posteriormente a Labov $(2006,2008)$ que há três sentidos para a formalidade que podem ser confundidos. No primeiro sentido, a formalidade é uma característica da língua, no qual o discurso está sujeito a regras. "A fala formal é marcada por uma estrutura especial; o estilo formal reduz a variabilidade e a espontaneidade da fala." (HORA, 2014, p. 21).

No segundo sentido, a formalidade ou informalidade são formas de descrever características da situação de uso e não de língua em si. Essas características da situação de uso podem ter a ver com tom de afetividade, ou seja, uma situação formal, exige um tom de seriedade e polidez. Para Labov (2008), "é a formalidade do contexto que faz com que um falante preste mais atenção a sua fala" (HORA, 2014, p. 21). Por fim, no terceiro sentido, "a formalidade se refere a um modo técnico de descrição, em que o estabelecimento pelo analista das regras que governam o discurso é explícito ao máximo" (HORA, 2014, p. 21).

Como já dito, grande parte dos estudos variacionistas vêm mostrando que há uma mudança em curso na sobreposição da variante 
ter pela variante haver em sentido existencial, fato que trazemos também neste texto, pois, ter ainda mantêm a grande maioria das ocorrências em sentido existencial em nossa amostra. No tipo de registro $E F$, embora com menor quantidade de dados totais, é clara a grande quantidade de ocorrências em vista das variantes haver e existir, apesar de estas aparecerem em maior quantidade no $E F$ que nos $D 2$ e DID.

Em resumo, podemos inferir, com base em nossos dados e com base na literatura sobre o fenômeno em tela que, quanto mais formal a fala do indivíduo, mais este usa as variantes de prestígio da língua, e mais ele usará a variante haver. análise.

A seguir, a terceira variável linguística em relevância nesta

\section{Concordância entre o verbo e o Sintagma Nominal - SN}

Grupo de fatores selecionados em quarto lugar na ordem de relevância, a concordância entre o verbo e o $S N$ destaca-se, em especial, por sabermos que o uso do verbo haver enquanto existencial é restrito à impessoalidade (SACCONI, 2001; BECHARA, 2009; CUNHA; CINTRA, 2010), ou seja, quando o verbo permanece no singular. Vejamos a atuação da variável em nossos dados.

Tabela 4 - Atuação da variável concordância entre o verbo e o SN sobre o verbo haver

\begin{tabular}{cccc}
\hline FATORES & Aplica/total & Percentual & P.R. \\
\hline verbo singular $\rightarrow$ SN plural & $71 / 162$ & $43,8 \%$ & $\mathbf{0 , 8 1 5}$ \\
verbo singular $\rightarrow$ SN singular & $384 / 1980$ & $19,4 \%$ & 0,492 \\
verbo plural $\rightarrow$ SN plural & $5 / 125$ & $4 \%$ & 0,195 \\
\hline Input 0,141 & \multicolumn{3}{c}{ Significance $=0,017$}
\end{tabular}

Fonte: elaboração própria.

A Tabela 4 nos revela que apenas o fator Verbo singular $\rightarrow S N$ plural é aliado de haver com PR de 0,815, enquanto que os fatores Verbo singular $\rightarrow$ SN singular, com PR de 0,492 e Verbo plural $\rightarrow$ SN plural com PR de 0,195 inibem seu uso, afinal, tratar-se-ia de hipercorreção, ou seja, seu uso seria considerado forma errônea na gramática normativa e, dentre todos os nossos dados, encontramos apenas 05 ocorrências dessa natureza, como apresentado no excerto (16). 
os moviMENtos popuLAres... constrangeram... até as For-ças ArMAdas... chegando ao PONto que dentro dos próprios... quartéis... haverem grupos... CONtra... atitudes... DE... oficiais... (PORCUFORT, EF, 36)

Vejamos melhor esses resultados.

As construções formadas por verbo singular $\rightarrow$ SN plural são aquelas ditas impessoais, como em:

(16) por-que num tem condiçõos de um carro... passar duzentos quilômetro por hora (PORCUFORT, D2, 11, Inf. 01)

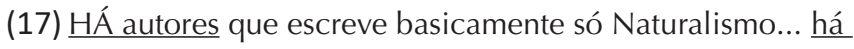
autores que escreve basicamente só Realismo... e há autores que misTUram... as tendências... né?... (PORCUFORT, $\mathrm{EF}, 36)$

(18) essa coisa de você comprar um tecido e mandar fazer uma blusinha uma coisinha isso pegava mal... existe dessas pessoas né?... (PORCUFORT, DID, 12)

Esses excertos nos mostram que os fortalezenses são favoráveis à impessoalidade, mesmo quando não necessário, como no excerto (19), com o verbo existir, que nos faz acreditar tratar-se de um caso claro de hipercorreção, no qual o verbo pessoal está no singular com um SN plural. Para exemplificar os demais fatores da variável, vejamos os excertos (20) e (21), abaixo.

(19) aquela COlsa de pequena burguesia mesmo né? que é um horror o que há de mais nojento na nossa sociedade né?... (PORCUFORT, DID, 12)

(20) o maior representante e o maior representante do Naturalismo é o Aluísio de Azevedo... houveram OUtros... (PORCUFORT, EF, 36)

Outra questão que devemos expor sobre nossos dados é com relação ao plural do verbo ter no presente de indicativo: têm. Algumas questões devem ser pontuadas aqui. Em primeiro lugar, encontramos 120 ocorrências de ter no presente do indicativo no plural, mas sabemos que essa diferenciação só ocorre na escrita e, a partir do contexto do discurso, pois não há qualquer diferença entre tem e têm na fala. Dessa maneira, explicamos grande quantidade de dados de plural para o verbo ter.

Esse grupo de fatores também foi estudado em Dutra (2000), como flexão de número e mostra que a não concordância é mais significativa 
com haver e existir. A seguir, apresentamos os resultados referentes a segunda variável extralinguística relevante em nosso estudo.

\section{Faixa etária}

Frequentemente selecionada como relevante para a variação dos verbos existenciais, a faixa etária foi selecionada como a quinta variável relevante da análise de haver vs. ter com dados do PORCUFORT. Vejamos sua atuação a partir da Tabela 5.

Tabela 5 - Atuação da variável faixa etária sobre o verbo haver

\begin{tabular}{cccc}
\hline FATORES & Aplica/total & Percentual & P.R. \\
\hline Faixa etária III & $209 / 855$ & $24,4 \%$ & $\mathbf{0 , 6 1 9}$ \\
Faixa etária I & $120 / 616$ & $19,5 \%$ & 0,440 \\
Faixa etária II & $131 / 796$ & $16,5 \%$ & 0,418 \\
\hline
\end{tabular}

Input 0,141

Significance 0,017

Fonte: elaboração própria.

Como esperávamos em nossas hipóteses, a Tabela 5 nos mostra a faixa etária III (de 51 anos em diante) como beneficiadora de haver, com PR de 0,619, enquanto que as faixas de indivíduos mais jovens, faixa I (22 a 35 anos) e faixa II (36 a 50 anos) desfavorecem haver, com PRs de 0,440 e 0,418 respectivamente, em detrimento de ter (PRs de 0,560 para a faixa I e 0,582 para a faixa II).

Esses resultados confirmam os de Batista (2012), Callou e Avelar (2000) e Dutra (2000), pesquisas que revelaram a faixa etária II como aliada de haver. Como sabemos, é através das análises das faixas etárias, que, a partir de uma análise em tempo aparente podemos vislumbrar uma possível mudança em progresso. Partindo desse pressuposto, procuramos avaliar, através da faixa etária, se há ou não mudança em progresso na variação dos verbos existenciais. Vejamos o Gráfico 2. 


\section{Gráfico 2 - Pesos relativos em função da faixa etária entre as variantes}

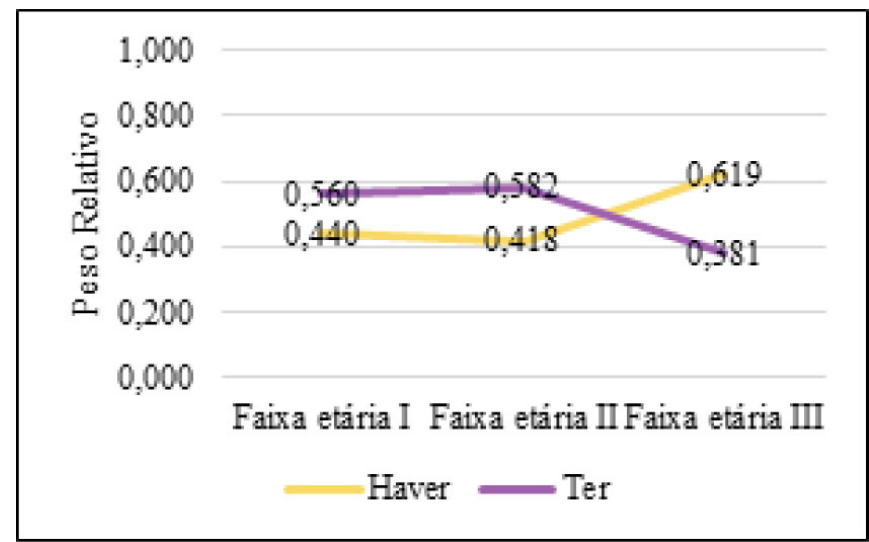

Fonte: elaboração própria.

Como vemos no Gráfico 2, a variante inovadora, o verbo ter, não apresenta um uso maior da faixa I, decrescendo na faixa II e faixa III, o que poderia caracterizar uma possível mudança em progresso, como preconizada por Labov (2001).

Dessa forma, podemos dizer que, no falar culto de Fortaleza-CE da década de 1990, visualizamos apenas uma variação estável entre haver e ter, sem indícios de mudança em progresso, no momento, o que refuta nossa hipótese inicial.

Vejamos, a seguir, a sexta variável selecionada como relevante na análise entre haver vs. ter.

\section{Repetição do verbo no mesmo enunciado}

Nossa hipótese para a testagem dessa variável, que se tornou a sexta em relevância para haver, se deu a partir do contato com nossos dados, pois percebemos a ocorrência de repetição do verbo num mesmo enunciado e decidimos testá-la também, hipótese esta que foi confirmada. 
Tabela 6 - Atuação da variável repetição do verbo no mesmo enunciado sobre o verbo haver

\begin{tabular}{cccc}
\hline FATORES & Aplica/total & Percentual & P.R. \\
\hline repetição & $24 / 57$ & $42,1 \%$ & $\mathbf{0 , 7 6 9}$ \\
não repetição & $436 / 2210$ & $19,7 \%$ & 0,492 \\
\hline Input 0,141 & & \multicolumn{2}{c}{ Significance $=0,017$}
\end{tabular}

Fonte: elaboração própria.

Como nos mostra a Tabela 6, a repetição do verbo no mesmo enunciado é aliada do verbo haver com PR de 0,769 , enquanto que a não repetição inibe haver, $(0,492)$ em benefício de ter $(0,508)$. Inferimos que essa repetição se dá a partir da intenção do falante em permanecer com um padrão de correção gramatical inclusive em sua fala. Em alguns casos, podemos reconhecer padrões de hipercorreção. Vejamos dois exemplos de repetição de haver no mesmo enunciado nos excertos (22) e (23).

(21) é... exatamente... e hoje há há há há dois problema sério do do Brasil é... (PORCUFORT, D2, 45, Inf. 01)

(22) haVIA:.... havia assim um aumento de paSSAgem ((toca o telefone))... NUM ERA:: \{num ERA... PRA HAVER um aumento de (PORCUFORT, DID, 22)

Nos dois excertos acima, identificamos que o indivíduo, quando da construção do seu raciocínio durante a fala, busca reafirmar a escolha da variante haver, assim como na correta colocação do SN na frase; como podemos ver, o conteúdo da frase é mais complexo, e geralmente traz uma introdução a um tema que ainda será exposto pelo falante.

A seguir, a sétima variável em relevância para esta análise.

\section{Presença de elementos à esquerda do verbo}

A presença de elementos à esquerda do verbo apresentou-se de forma bastante favorável ao verbo haver com 04 fatores favorecedores, como exposto na Tabela 7. 
Tabela 7 - Atuação da variável presença de elementos à esquerda do verbo sobre o verbo haver

\begin{tabular}{cccc}
\hline FATORES & Aplica/total & Percentual & P.R. \\
\hline preposição & $10 / 27$ & $37 \%$ & $\mathbf{0 , 6 7 7}$ \\
advérbio & $69 / 300$ & $23 \%$ & $\mathbf{0 , 5 7 1}$ \\
ausência & $246 / 1127$ & $21,8 \%$ & $\mathbf{0 , 5 2 4}$ \\
conjunção & $76 / 352$ & $21,6 \%$ & $\underline{\mathbf{0 , 5 1 6}}$ \\
negação & $58 / 446$ & $13 \%$ & 0,376 \\
pronome & $1 / 15$ & $6,7 \%$ & 0,292 \\
\hline Input 0,141 & \multicolumn{3}{c}{ Significance $=0,017$}
\end{tabular}

Fonte: elaboração própria.

O fator preposição foi a maior aliada da aplicação, com PR de 0,677 , seguido de advérbio $(0,571)$, e, mesmo pouco acima da neutralidade, os fatores ausência $(0,524)$ e conjunção $(0,516)$, como visualizamos na Tabela 7 . Já os fatores negação e pronome $(0,376$ e 0,292) não privilegiaram haver, sendo aliados de ter com pesos de 0,624 e 0,708, respectivamente. Nossa hipótese para essa variável foi confirmada para o verbo ter, já que não lançamos mão de hipóteses, sobre ela, para o verbo haver.

Como exemplos dessa variável, vejamos os excertos abaixo, correspondentes aos fatores relevantes na ordem respectiva da tabela.

(23) seria uma recção... mas o inverso não se dá... nem toda recção seria uma transitividade PRA haver transitividade ((tosse de ouvinte))... era preciso que houvesse um (PORCUFORT, EF, 25)

(24) S::EMpre houve da parte do homem o interesse de ter uma língua universal (PORCUFORT, D2, 47, Inf. 02)

(25) O há um desestímu\{lo geral né? (PORCUFORT, D2, 07, Inf. 01)

(26) toda vida que há corte em investimento... conseqüentemente HÁ desemprego... né?... (PORCUFORT, D2, 45, Inf. 02) 
Em nenhum desses estudos sobre os verbos existenciais, a variável presença de elementos à esquerda do verbo foi relevante para as análises entre as variantes. Fato que mais uma vez se destaca em nossos resultados, e que podemos inferir que isso se dá pelo elevado número de dados em nossa amostra, o que não ocorreu nos estudos supracitados.

Sigamos em nossa análise com a última variável social relevante para a análise de haver vs. ter.

\section{Sexo}

Uma das variáveis mais influentes na variação entre os verbos existenciais é a variável sexo do informante, nossa oitava variável em relevância para aplicação de haver.

Tabela 8 - Atuação da variável sexo sobre o verbo haver

\begin{tabular}{cccc}
\hline FATORES & Aplica/total & Percentual & P.R. \\
\hline feminino & $214 / 1070$ & $20 \%$ & $\mathbf{0 , 5 4 7}$ \\
masculino & $246 / 1197$ & $20,6 \%$ & 0,458 \\
\hline Input 0,141 & & \multicolumn{2}{c}{ Significance $=0,017$}
\end{tabular}

Fonte: elaboração própria.

Os dados da Tabela 8 revelam-nos que as mulheres favorecem haver com PR de 0,547, enquanto os homens desfavorecem a variante padrão com PR de 0,458, em detrimento da não padrão $(0,542)$, como esperado em nossas hipóteses e preconizado por sociolinguistas como Chambers e Trudgill (1980), que verificam que as mulheres são mais sensíveis ao uso de formas prestigiadas em situações de variação estável.

Esse resultado é corroborado por Callou e Avelar (2000), Martins e Callou (2003) - embora os homens do nível primário sejam beneficiadores de haver -, mas contrário a Dutra (2000) onde os homens foram aliados da variante padrão, comportamento não esperado.

É muito interessante, ao propormos os paralelos entre nossa pesquisa e as demais pesquisas sobre o fenômeno em pauta, conseguirmos visualizar as tendências de mudança nos dados encontrados no PB. 
Dizemos isso, porque o estudo de Martins e Callou (2003) indica que os falantes de sexo masculino, de nível superior, na década de 1970 são aliados de haver, enquanto que, na década de 1990, são os falantes de sexo feminino que privilegiam a regra.

Vejamos: o NURC, assim como o PORCUFORT, é formado apenas por indivíduos de nível superior completo. Levando em consideração o acesso, ao ensino superior no Brasil, desde a época das primeiras universidades brasileiras, ser escasso e, para muito poucos, era mais difícil, ainda, o acesso para as mulheres, diante do forte papel social dado à mulher, de ser apenas, e, unicamente, a detentora do lar, sem a necessidade de continuar seus estudos, em especial, na década de 1970, quando os dados da primeira amostra do NURC foram coletados. Dizemos em especial, porque o passar dos anos trouxe gerações de mulheres protagonizadoras de muitas mudanças sociais.

Ou seja, os homens da década de 1970 são beneficiadores de haver, porque não havia, ainda, a força do sexo feminino na academia; não havia, ainda, muitas mulheres com o objetivo de seguir a carreira acadêmica e profissional, o que as fez, como afirma Labov (2001, 2006, 2008), sentir a necessidade de apresentar, através da língua, sua afirmação social. A busca por afirmação social feminina foi cada vez mais se fortalecendo ao final do século XX.

Nos dados de Martins e Callou (2003), a segunda coleta do NURC, em 1990, já apresenta as mulheres mais aliadas à variante padrão que os homens. Esse fato corrobora tudo o que já vem sendo discutido na Teoria da Variação e Mudança Linguística de Weinreich, Labov e Herzog (2006): a influência do papel social na variação e mudança linguística.

A seguir, a última variável relevante na análise haver vs. ter: a posição do $S N$.

\section{Posição do Sintagma Nominal - SN}

A variável posição do SN, também estudada por Dutra (2000), mostrou-se relevante para a variação entre haver vs. ter em nosso estudo, selecionada como a nona e última em ordem de relevância. Vejamo-la na Tabela 9. 
Tabela 9 - Atuação da variável posição do SN sobre o verbo haver

\begin{tabular}{cccc}
\hline FATORES & Aplica/total & Percentual & P.R. \\
\hline posposto & $450 / 2175$ & $20,7 \%$ & $\underline{\mathbf{0 , 5 0 9}}$ \\
anteposto & $10 / 92$ & $10,9 \%$ & 0,304 \\
\hline Input 0,141 & \multicolumn{3}{c}{ Significance $=0,017$}
\end{tabular}

Fonte: elaboração própria.

Como podemos ver, apenas o fator posposto é favorecedor de haver com PR de 0,509, ou seja, pouco acima do ponto neutro, enquanto o fator anteposto tem PR desfavorecedor de haver $(0,304)$ e favorecedor de ter $(0,696)$.

Traçando um paralelo com o estudo de Dutra (2000) que analisou seus dados a partir de análise estatística, esta variável não se apresentou como relevante, mas Dutra (2000) a destaca quanto à quantidade de dados, onde o fator posposto $(38,4 \%)$ é superior em frequência ao fator anteposto $(30,4 \%)$ para haver.

Sobre esses fatores, acreditamos, como Callou, Batista e Almeida (2015), que haver possui uma relação semântica de sujeito não-agente, ou sem sujeito, mas com um tema. E, mais, que haver impessoal transitivo direto exige o objeto direto, posposto, como no excerto (28).

Vejamos, então, nos excertos, a seguir, ilustrações dessa variável, um para o verbo com o $S N$ posposto, fator aliado de haver, e outro para ter com o $S N$ anteposto, seu beneficiador.

(27) ...além disso há o problema da fome... (PORCUFORT, D2, 07, Inf. 02)

(28) lastro é a quantidade em ouro que deveria ter CERto? (PORCUFORT, DID, 29)

Dessa forma, mais uma variável se apresenta relevante de forma inédita para os estudos sobre os existenciais no PB.

Além desses resultados, podemos verificar ainda, a partir do input dessa rodada, quais os percentuais de probabilidade de um falante culto fortalezense da década do corpus, falar uma ou outra variante, com podemos ver no Gráfico 3. 


\section{Gráfico 3 - Probabilidade de ocorrência das variantes em análise}

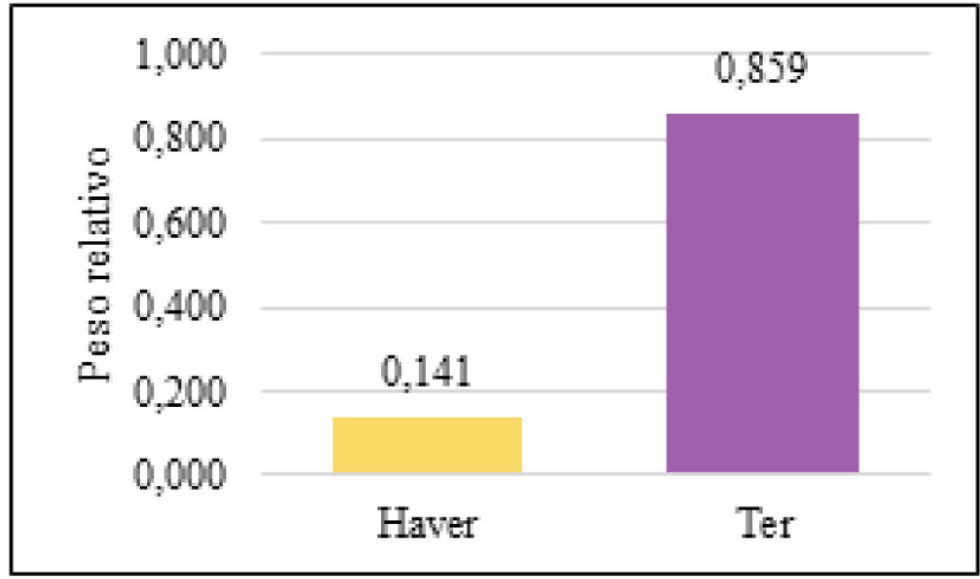

Fonte: elaboração própria.

Interessante verificarmos que, em Souza (2015), com dados do NORPOFOR ${ }^{10}$, a probabilidade de haver ser falado por um fortalezense de nível escolar básico na década de 2000 é de 0,013 contra, em nossos dados, 0,141 , ou seja um aumento significativo oriundo, muito provavelmente, das características sociais dos falantes do PORCUFORT. Embora não possamos deixar de visualizar a alta probabilidade de uso de ter existencial, acreditamos que, por tratar-se de um fenômeno de variação estável, o uso dos verbos existenciais está intrinsecamente ligado ao estilo do falante.

\section{CONSIDERAÇÕES FINAIS}

Nosso estudo procurou realizar uma descrição da variação entre os verbos haver e ter no português culto de indivíduos fortalezenses, objetivando descobrir além das frequências de uso das variantes, quais fatores beneficiam a um e ao outro verbo. Poderíamos ter analisado a interação com o verbo existir, assim como verificar a influência de outras variáveis, mais análises. Isso fica para uma outra oportunidade.

10 Projeto Norma Oral do Português Popular de Fortaleza-CE. Maiores detalhes Araújo, Viana e Pereira (2018b). 
Nossa análise sobre os verbos existenciais confirmam a maior parte de nossas hipóteses para a variação em tela. A primeira hipótese foi ratificada, pois a ocorrência geral de ter (79,7\%) é superior a haver (20,3\%). Em segundo, a hipótese de que os tempos do presente, a presença de elementos à esquerda do verbo, os tipos de registro D2, o sexo masculino e a faixa I favorecem o verbo ter foi confirmada para todos os fatores. Em terceiro, a hipótese de o verbo haver ser privilegiado pelos fatores traço semântico do SN [-animado], pelos tempos no passado, pela repetição do verbo no mesmo enunciado, a partir do sexo feminino, a faixa etária III e pelo tipo de registro $E F$, também foi confirmada. Em último, quanto a estarmos diante de uma avançada mudança em progresso, a qual ter existencial esteja suplantando o uso de haver existencial, a hipótese foi refutada, pois a análise das faixas etárias apresenta apenas uma variação estável.

Apenas três de nossas hipóteses não puderam ser confirmadas ou refutadas. Duas delas, por não terem sido selecionadas como relevantes para a variação entre haver vs. ter, que foram a presença de modalizador e presença da variável na fala do documentador; e, a terceira, a variável tipo de oração que foi retirada dos dados por problemas na análise.

Agradecemos à Fundação Cearense de Apoio ao Desenvolvimento Científico e Tecnológico - FUNCAP, pela bolsa concedida para realização desta pesquisa e à Secretaria de Educação Básica do Ceará - SEDUC-CE pela concessão de licença para estudos de mestrado e doutorado.

\section{REFERÊNCIAS}

ALMEIDA, N. M. de. Gramática Metódica da Língua Portuguesa. São Paulo: Saraiva, 1999.

ARAúJO, A. A. de; VIANA, R. B. de M.; PEREIRA, M. L. de S. O Projeto Descrição do Português Oral Culto de Fortaleza - PORCUFORT: das origens aos dias atuais. Web Revista SOCIODIALETO, [S.I.], v. 8, n. 24, p. 174-198, jun. 2018a. Disponível em: $<$ http://sociodialeto.ojs.galoa.com.br/index.php/sociodialeto/article/view/39>. Acesso em: 30 jun. 2018.

O banco de dados NORPOFOR. In: Fotografias sociolinguísticas do falar de Fortaleza-CE. Fortaleza: EdUECE, 2018b. p. 15-66.

BAGNO, M. Gramática Pedagógica do Português Brasileiro. São Paulo: Parábola Editorial, 2011.

BATISTA, P. G. Ter e Haver existenciais na fala culta do Rio de Janeiro, Salvador e Porto Alegre: do social ao linguístico. 2012. 70 f. Dissertação (Mestrado em Letras Vernáculas) - Programa de Pós-Graduação em Letras Vernáculas, Faculdade de Letras, Universidade 
Federal do Rio de Janeiro, Rio de Janeiro, 2012. Disponível em: <http://www.letras.ufrj. br/posverna/mestrado/BatistaPG.pdf>. Acesso em: 26 jun. 2016.

BECHARA, E. Moderna Gramática Portuguesa. 37. ed. Rio de Janeiro: Editora Lucerna, 2009.

BERLINCK, R. de A.; DUARTE, M. E. L.; OliveIRA, M. de. Predicação. In: KATO, M. A.; NASCIMENTO, M. do. (Orgs.). Gramática do português culto falado no Brasil - a construção da sentença. Campinas: Editora da Unicamp, 2009. v. 3. p. 97-188. Disponível em: $\quad<$ https://edisciplinas.usp.br/pluginfile.php/284762/mod_resource/content/1/ GRAMATICA \%20DO\%20PORTUGU\%C3\%8AS\%20CULTO\%20FALADO $\% 20 \mathrm{NO} \% 20$ BRASIL.pdf>. Acesso em: 05 mar. 2018.

BORTONI-RICARDO, S. M.; ROCHA, M. do R. O Ensino de português e a Variação Linguística em sala de aula. In: MARTINS, M. A.; VIEIRA, S. R.; TAVARES, M. A. (Orgs.). Ensino de português e Sociolinguística. São Paulo: Parábola Editorial, 2014.

CALLOU, D.; BATISTA, P.; ALMEIDA, É. “Houveram/Tiveram muitas reuniões”: construções existenciais e concordância verbal. Cuadernos de la Alfal, n. 7, mar. 2015, p. 185-194. Disponível em: <www.mundoalfal.org/sites/default/files/revista/07_cuaderno_011.pdf>. Acesso em: 24 abr. 2018.

CALLOU, D.; AVELAR, J. O. de. Sobre ter e haver em construções existenciais: variação e mudança no português do Brasil. Revista Gragoatá, n. 9, p. 85-100, 2000. Disponível em: <http://www.academia.edu/15828109/Sobre_TER_e_HAVER_ em_constru\%C3\%A7\%C3\%B5es_existenciais_varia\%C3\%A7\%C3\%A3o_e_ mudan\%C3\%A7a_no_Portugu\%C3\%AAs_do_Brasil>. Acesso em: 14 maio 2018.

CAMACHO, R. G. Norma culta e variedades linguísticas. In: UNESP. Prograd. Caderno de formação: formação de professores didática geral. São Paulo: Cultura Acadêmica, 2011. p. 34-49. v. 11. Disponível em: <https://disciplinas.stoa.usp.br/pluginfile.php/174227/ mod_resource/content/1/01d17t03.pdf> Acesso em: 23 set. 2017.

CARVALHO, O. L. de S. Variação linguística e ensino: uma análise dos livros didáticos de português como segunda língua. In: BAGNO, M. Linguística da norma. São Paulo: Edições Loyola, 2004. p. 267-290.

CEGALLA, D. P. Novíssima gramática da língua portuguesa. São Paulo: Nacional, 1978. CHAMBERS, J. K.; TRUDGILL, P. Dialectology. 2. ed. Cambridge: Cambridge University Press, 1980.

CUNHA, C.; CINTRA, L. L. F. Nova gramática do português contemporâneo. 5. ed. Rio de Janeiro: Lexikon, 2010.

DUTRA, C. de S. Ter e haver na norma culta de Salvador. 2000. 186 f. Dissertação (Mestrado em Letras) - Programa de Pós-Graduação em Letras e Linguística, Universidade Federal da Bahia, Salvador, 2000. 
HORA, D. da. Estilo: uma perspectiva variacionista. In: GÖRSKI, E. M.; COELHO, I. M. L.; SOUZA, C. M. N. de. (Orgs.). Variação estilística - reflexões teórico-metodológicas e propostas de análise. Coleção Linguística. Florianópolis: Insular, 2014. v. 3. p. 19-30.

LABOV, W. Padrões sociolinguísticos. Tradução de Marcos Bagno, Maria Marta Pereira Scherre, Caroline Rodrigues Cardoso. São Paulo: Parábola Editorial, 2008.

LABOV, W. The social stratification of English in New York city. 2. ed. Cambridge: University Press, 2006.

LABOV, W. Principles of Linguistic Change: Social Factors. Oxford: Blackwell, 2001. v. 2 .

MARTINS, L.; CALLOU, D. Mudança em tempo aparente e em tempo real: construções ter/haver existenciais. In: ENCONTRO DO CÍRCULO DE ESTUDOS LINGUÍSTICOS DO SUL, 5., 2003, Curitiba. Anais Eletrônicos... Curitiba: Mídia Curitibana, 2003. p. 820825. Disponível em: <http://celsul.org.br/Encontros/05/pdf/114.pdf>. Acesso em: 26 jun. 2016.

MENDES, R. B. Língua e variação. In: FIORIN, J. L. (Org.). Linguística? Que é isso? São Paulo: Contexto, 2015. p. 111-135.

MOLLICA, M. C. A relevância das variáveis não linguísticas. In: MOLLICA, M. C.; BRAGA, M. L. (Orgs.). Introdução à sociolinguística - o tratamento da variação. 2. ed. São Paulo: Contexto, 2004. p. 27-31.

PERINI, M. A. Gramática do português brasileiro. 2. imp. São Paulo: Parábola Editorial, 2013.

ROCHA LIMA, C. H. da. Gramática normativa da língua portuguesa. Rio de Janeiro: José Olympio, 2001.

SACCONI, L. A. Nossa gramática: teoria e prática. São Paulo: Saraiva, 2001.

SAID ALI, M. Dificuldades da língua portuguesa. 7. ed. Rio de Janeiro: ABL: Biblioteca Nacional, 2008. Disponível em: <http://www.academia.org.br/sites/default/files/ publicacoes/arquivos/dificuldades_da_lingua_portuguesa_-_cams_-_para_internet.pdf>. Acesso em: 19 abr. 2018.

SAMPAIO, M. L. P. Estudo diacrônico dos verbos TER e HAVER: duas formas em concorrência. Assis-SP: Nigro, 1978. Disponível em: <https://pt.scribd.com/ 
document/159053795/Estudo-Diacronico-Dos-Verbos-TER-e-HAVER-Maria-LuciaPinheiro-Sampaio>. Acesso em: 18 abr. 2018.

SANKOFF, D.; TAGLIAMONTE, S. A.; SMITH, E. Goldvarb X: a variable rule application for Macintosh and Windows. University of Toronto, Department of Linguistics, 2005. Software. Disponível em: <http://individual.utoronto.ca/tagliamonte/Goldvarb/GV index.htm\#ref>. Acesso em: 10 jun. 2017.

SOUZA, F. F. de. Tem chance de haver ainda existir no falar popular? A variação dos verbos existenciais em amostra do NORPOFOR. 2015. 105 f. Dissertação (Mestrado em Linguística Aplicada) - Programa de Pós-Graduação em Linguística Aplicada, Universidade Estadual do Ceará, Fortaleza, 2015. Disponível em: <http://www.uece.br/ posla/dmdocuments/Disserta\%C3\%A7\%C3\%A30\%20-\%20Francisco\%20F.\%20de\%20 Souza.pdf>. Acesso em: 21 jun. 2016.

TARALLO, F. A Pesquisa Sociolinguística. São Paulo: Ática, 1990.

VIANA, R. B. de M. Tem mais existir que haver no falar dos fortalezenses: o papel dos fatores sociais na variação dos verbos existenciais. In: ARAÚJO, A. A. de; VIANA, R. B. de M.; PEREIRA, M. L. de S. Fotografias sociolinguísticas do falar de Fortaleza-CE. Fortaleza: EdUECE, 2018. p. 95-125.

VITÓRIO, E. G. de S. L. A. Construções existenciais com os verbos ter e haver na fala e na escrita: uma análise comparativa. 2013. 29 f. Relatório de Pós-Doutorado (Pósdoutorado Júnior em Letras Vernáculas) - Universidade Federal do Rio de Janeiro, Rio de Janeiro, 2013.

VITÓRIO, E. G. de S. L. A. Ter e haver existenciais: gramática versus uso. Revista Urutágua - acadêmica disciplinar, n. 21, p. 90-98, maio/ago. 2010a. Disponível em: <periodicos. uem.br/ojs/index.php/Urutagua/article/viewFile/7472/5631>. Acesso em: 24 abr. 2018.

WEINREICH, U.; LABOV, W.; HERZOG, M. I. Fundamentos empíricos para uma teoria da mudança linguística. Tradução de Marcos Bagno. São Paulo: Parábola Editorial, 2006.

Recebido em: 11/12/2019

Aceite em: 20/12/2019 